Medicine Updates

Faculty of medicine

October 2020, volume 3, https://muj.journals.ekb.eg

dean@med.psu.edu.eg

vice_dean_postgraduate@med.psu.edu.eg

DOI: $10.21608 /$ muj.2020.41320.1026

ISSN : 2682-2741

Submitted: $31 / 8 / 2020$

Accepted : 20/9/2020

Pages:60-74

\title{
Establishment of Health Pharmacy Project to Ensure Medication Safety in Port said
}

Dr. Rasha Fawzey Fahmy Aboslema Pharmacit at Chest hospital

Dr . Dina Mahmoud Morsy Mohamed Pharmacist at Health Care

Authority Supply Management

Dr . Yasmin Mohamed Mohamed Gad Head of pharmacy department at

Shark Elnawade medical center

Dr . Haidy Mohamed Alsayed Mohamed Pharmacist at Shark Elnawady medical center

Dr . Amira Mohamed Gaber Elkafrawy Pharmacist at Shark Elnawady medical center

Dr . Ramy Abdu Mohamed Elfarargy manager in free therapy administration at directorate of health affair

Dr . Mohamed Hasan Mostafa Drakoun Pharmacist at 19011 pharmacy

Dr . Mohamed Mohamed Mohamed Gad Manager of Elradwan medical unit 


\begin{abstract}
$\underline{\text { Abstract }}$
Background: Pharmacists are the link between physicians and patients who check prescriptions before dispensing the drug to the patients to make sure that the they take the correct medication.

Giving the incorrect drugs or instructing wrong usage may have serious effects on patient.

The pharmacist gives medical advices about the treatment of complex diseases as diabetes or arthritis.
\end{abstract}

Aim of the study: To provide an excellent medical service to people through our pharmacy, study SWOT analysis for the project, calculate and estimate the total budget of this projet, estimate Legal study, Environmental study and Social study, establishment of catastrophe plan, study methods to cover the negative cash flow balance, discuss Feasibility of the project and identify risk management plan.

Methedology: SWOT analysis, TOWS study, Feasibility study, Budgeting of the project, Legal study, Environmental study, Political study,Social study, catastroph plan, methods of cost reduction and establishment of:risk management plan, financing plan and development plan

Conclusion: To open new pharmacy you should have advantages and more services over your surrounded compititors. Study SWOT analysis is important to supply unique pharmacological services.

It is mandatory to plan for the Budgeting of the project to include losses and maximise profits.

Estimation of political study, legal study, environmental study and social study are essential establishment of new pharmacy.

Catastrophe plan is procedures have been established to respond to any external emergency and the expected risks such as Covid-19.Feasibility of the project of the project important for project success.

Key words: Medication, Safety, Pharmacy, Health, Project . 


\section{$\underline{\text { Introduction }}$}

Pharmacists are the link between doctors and patients who give medical instructions to the patient to increase the desired value of the drug and decrease the side effects of it. The basic responsibility of a pharmacist is to check prescriptions from doctors before dispensing the drug to the patients to make sure that the patients don't take the wrong medications or take an wrong medicine dose.

Pharmacists are also the guides of the side effects of drugs.

A lot of their work is related to safety of patient, so a pharmacist assures that the patient don't take a medication that may be allergic, or that will interact with food or another drug he is already taking. Although preventing dangerous drug interactions is primarily a doctor's role and responsibility, pharmacists make drug interactions check. A pharmacist give medical advices about the management of complex diseases. Pharmacists might also educate other health care staff such as doctors or nurses about pharmacology-based issues or drug management and contribute most in the campaign to stop the incorrect use of antibiotics, habit forming and aphrodisiac medications .(Sinha, 2014) 


\section{Methodology}

SWOT Analysis(Shewan, 2020)

\begin{tabular}{|c|c|c|}
\hline Fact & Strengths & Weakness \\
\hline \multirow[t]{2}{*}{ Internal } & $\begin{array}{l}\text { (1) Fast service \& free } \\
\text { delivery } \\
\text { (2) Clinical pharmacists with } \\
\text { up-to-date knowledge } \\
\text { with new treatment } \\
\text { stratiges and new remedies } \\
\text { (3) Online website plus } \\
\text { online orders } \\
\text { (4) Working } 24 \text { hrs/week } \\
\text { (5) Location of the pharmacy } \\
\text { is unique } \\
\text { (6) Pharmacy is large sized }\end{array}$ & $\begin{array}{l}\text { (1) Lack of experience with new } \\
\text { employers } \\
\text { (2) Lack of selling skills } \\
\text { (3) Marketing deficiency } \\
\text { (4) Limited financial resources } \\
\text { (5) Workers high turnover } \\
\text { (6) No standard classification for } \\
\text { medical devices }\end{array}$ \\
\hline & Opportunities & Threats \\
\hline External & $\begin{array}{l}\text { (1) Neibouring clinics and } \\
\text { hospitals of multiple } \\
\text { specialities } \\
\text { (2) Two way large street } \\
\text { (3) Neibouring people with } \\
\text { high economic position } \\
\text { (4) Crowded area } \\
\text { (5) No many pharmacies in } \\
\text { our area }\end{array}$ & $\begin{array}{l}\text { (1) Increase in market } \\
\text { competition } \\
\text { (2) Unpredictability of consumer } \\
\text { purchasing behavior } \\
\text { (3) Additional governmental } \\
\text { regulations and tax policies } \\
\text { (4) Pricing pressures presented by } \\
\text { chain pharmacies offers } \\
\text { (5) Expected shortfall of qualified } \\
\text { pharmacist by } 2020\end{array}$ \\
\hline
\end{tabular}


TWOS Study(Shewan, 2020)

\begin{tabular}{|l|l|}
\hline \multicolumn{1}{|c|}{ TW } & \multicolumn{1}{c|}{ OS } \\
\hline $\begin{array}{l}\text { Training staff plan to increase employee } \\
\text { selling skills }\end{array}$ & $\begin{array}{l}\text { Put advertising banners to attract } \\
\text { population in this two way large street }\end{array}$ \\
\hline Take loan to maximize our financial status & $\begin{array}{l}\text { By using online and delievery services } \\
\text { can reach our surrounded large } \\
\text { population }\end{array}$ \\
\hline $\begin{array}{l}\text { Store excess of medications to overcome } \\
\text { drug deficiency caused by corona }\end{array}$ & $\begin{array}{l}\text { Establish pharmacy store to meet } \\
\text { surrounded growing in our market }\end{array}$ \\
\hline $\begin{array}{l}\text { Employ qualified managers and increase } \\
\text { salaries to reduce turnover and meet high } \\
\text { market demand }\end{array}$ & $\begin{array}{l}\text { Promotional representatives from } \\
\text { pharmacy to neighbouhood clinics and } \\
\text { hospitals to make deal with them. }\end{array}$ \\
\hline
\end{tabular}

\section{Legal study (Chapter, 2008)}

1 - The pharmacist may not be an owner or partner in more than two pharmacies (Article 30 of the Law).

2 - A license to establish a pharmacy is only given to a pharmacist whose graduation has been at least a year in which he practiced the profession (Article 30 of the Law).

3 - The pharmacist who is referred to the pharmacy by inheritance or wills will be exempted from the period (Article 30 of the Law). 4 - It is permissible to license a pharmacy to a pharmacist for a government employee (also Article 30).

5 - The distance between the pharmacy that you will open and the nearest pharmacy should not be less than one hundred meters.

6 - The area of the pharmacy should not be less than 25 square meters, and the height should not be less than 2.6 meters in all parts of the pharmacy.

7 - The pharmacy should be above ground level or the sidewalk.

8 - The pharmacy-related ventilation should not be less than one sixth of the total area and all facilities, whether electricity or water, are available. 9 - To design a sketch of the pharmacy, showing its engineering dimensions and showing the distance between it and the pharmacy near it. 10 - There should be a design that contains the division of the place, the windows in it and the places designated for ventilation. 


\section{Political Study}

in some countries, the role of pharmacists is limited to dispensing medicines but in eygpt, Community pharmacies have an important role in the healthcare system. These facilities and pharmacists employed there are supposed to provide access to medicines, health promotion, and advice concerning the safe and effective use of pharmaceuticals.Considering the significant role of pharmacists in activities such as pharmaceutical care as well as the importance of affordability of medicines pharmacy markets are changing to become patient-focused and to improve access to medicines and market competitions between pharmacies .(MPCA, 2020)

\section{Environmental Study}

i. Narcotic drugs closed box put these drugs inside the lab of pharmacy away from patients

ii. Dispose of used syringes

Put all syringes, used needles and other sharp materials into a sharps disposal container immediately after they are used.

This will reduce the risk of needle sticks, cuts, and punctures.

iii. Dispose of expired drugs

1) Reverse Distribution and Your Pharmaceutical Waste is only an option if that medication is considered "reusable," meaning it hasn't been opened, used, or contaminated.

2) Disposal through a Waste Management Company If you can't utilize reverse distribution for your expired pharmaceuticals. .(Mcf Environmental Services, n.d.)

\section{Social Study}

1) Oneline websie

2) Offers on cosmemtic products

3) In body equipment for free for total body weight and length \& for body fats estimation

4) Blood glucose and Pressure measurement for free

5) Free home delievery

6) 24 hour service daily per week 


\section{Catastrophe plan}

\section{In Case of Fire}

1. Fire detection systems

Automatic detection system, like a detector that works when there is smoke or a temperature change, or manual, such as a switch an employee can pull if they find smoke or fires.(Webb, 2019)

2. Learn how to deal with fire

Fire plan foe evacuation and escape exits should be professionally designed, well displayed, and well-known by staff.

Ensure employees identifying fire hazards and what to do in the case of a fire. Employees should know the site of the nearest fire extinguisher, fire alarm, and the nearest two emergency exits. (Webb, 2019)

\section{Fire suppression systems}

Automatic fire suppression system include sprinkler systems, chemical suppression such as $\mathrm{CO}_{2}$ system and fire doors. It is essential that fire doors are never forced or propped open, as this destroys their effectiveness.(Webb, 2019)

\section{In Case of Infectious Microorganisms (such as COVID19)}

All staff must wear face masks and gloves

Deal with patients through separation wall window to avoid direct contact Continuously use alcohol and hand sanitizer

Pharmacy sterilization weekly.

\section{In Case of Violence Attack}

Establish camera system to record all events audio and visual Training the medical staff how to deal with and calm the attackers in order to preserve the lives of the workers and patients.

Call the emergency to contain the situation.

Employ security guards who are experts to deal with these situations. 


\section{Budgeting of The Project}

The capital

The capital $=800,000 \mathrm{LE}$

Fixed assets:

-building rent $=10,000 \mathrm{LE} /$ month for five years renting

-Machines (that will stay one year and will not be disposable)

$$
=25000 \mathrm{LE}
$$

Current Assests $=650,000 \mathrm{LE}$

Money and the source $=400,000 \mathrm{LE}$

Stocks, shares, stored material $=250,000 \mathrm{LE}$

Current assest $/$ capital $=650,000 / 800,000 \mathrm{LE}$

150,000/800,000 LE

The expenses ( costs)

Salaries $\rightarrow 40000 \mathrm{LE} /$ month

Rent $\rightarrow 10,000$ LE / month

All of the following are current costs $\rightarrow$ cost reduction

-Electricity $\rightarrow 2000$ LE / month

-Water $\rightarrow 500$ LE / 3 months

-Maintenance of building,machine $\rightarrow 500$ LE / month

-Cost of marketing $\rightarrow 2,000 \mathrm{LE}$

-Cost of sales $\rightarrow 240,000$ LE

-Bank installments $\rightarrow 220,000$ LE / 3months

Total cost $/$ unit service $=800000 / 350=2285.714 \mathrm{LE}$

Fixed cost/unit service $=150000 / 350=428.571 \mathrm{LE}$

Current cost/unit service $=650000 / 350=1857.142$ LE 
Methods to cover the negative cash flow balance

Recognizing obligation by putting supplies and other normal operating expenses on a credit card to take advantage of additional payment cycle time and rebates or rewards

From previous positive months of cash flow as maintaining positive cash flow is important to maintain success for long period of time.positive cash flow is a suitable indication of present financial situation. Short term loans help us to avoid accumulating debt.

Negotiation to postpone obligations and negotiate payment terms as setting invoice payment terms with customers so they know when to pay us and agreeing to our vendors payment terms so we know when to pay them and so adjusting these types of payment terms to improve cash flow for customer payment terms, decrease the number of days customers have to pay us .(Murphy, 2020)

\section{Feasibility of the project}

This project consists in setting up a pharmacy where all the products for personal care and medicines are sold along with the services provided by pharmacies such as public health checks

The pharmacy also provides a wide variety of treatments and medications as well as over-the-counter medications.

A team of licensed and trained pharmacists will be employed to dispense the drug and promote safe and effective use of the drugs. The project can also provide its services through the pharmacy's website on the Internet / or through the phone application where individuals can submit their requests to it.

The project aims to contribute to meeting the market needs of products and services provided by the pharmacy to individuals. .(el-tiqnea, 2020)

\begin{tabular}{|r|r|r|r|r|}
\hline & $1^{\text {st }}$ year & $2^{\text {nd }}$ year & $3^{\text {rd }}$ year & Sum \\
\hline The capital & $800000 \mathrm{LE}$ & $1000000 \mathrm{LE}$ & $1200000 \mathrm{LE}$ & $3000000 \mathrm{LE}$ \\
\hline The profit & $344826 \mathrm{LE}$ & $491032 \mathrm{LE}$ & $589238 \mathrm{LE}$ & $1473096 \mathrm{LE}$ \\
\hline
\end{tabular}




\section{Risk Management Plan}

\section{Management plan of natural disaster}

Earthquakes and surface collapse:(Rao et al., 2018)

Training workers in a disaster occurance and know emergency exits. Store substances which are fragile in low, closed boxes, and shelves near to wall.

Products which are flammable and toxic stored in closed boxes and on bottom shelve.

Set and support overhead light fixtures.

Fix wall deep cracks and ceilings cracks.

Repair unprotected electrical cords.

Establish safe location under furniture, as a heavy desk and far from glass material that could collapse and away from an inside wall or under a door frame.

Define safe places outdoors, far from buildings, trees, walls, overpasses, and or electrical lines.

Panademic / infectious / communicable diseases ( COVID-19, H1N1, etc) Training employees to use personal protections such as face mask and face sheild, wash hands, and use detergents and disinfectants constantly. Commitment to social separation and the use of a glass or plastic barrier in the area of interaction and communication with patients.

Provide oral and printed medical consultations and on the pharmacy's website.

Contact healthcare provider for immediate care instructions.

Reduce worker's panic and distress and make sure return to normal situations.(Rao et al., 2018)

\section{Fires}

\section{Management plan of man-made disaster}

Training workers in the fire evacuation plan and training them in the use of fire extinguishersof all kinds.

Determine fixed locations for fire extinguishers, while maintaining monthly maintenance and follow-up.

Determining the entrances and emergency exits and using the signs and light signs to identify them, with fixing a fixed point for gathering outside the establishment for the staff gathering.

Appoint a team of workers to manage the situation and evacuate patients and workers.

Emergency call and firefighting units to contain the fire. 
Terrorist attack and work place violence

Training the workers on how to deal with and calm the attacker in order to preserve the lives of the workers and sick patients.

Calling the emergency and emergency to contain the situation.

Rumors and malevolence from competitors

Improving workers' communication skills, training courses and workshops on how to deal with patients who are reluctant to the place and periodically monitoring the performance of workers.

Permanent improvement and development of the services provided.

Paying attention to positive advertising by publishing it orally and paper publications and publishing it on the website of the pharmacy on the Internet and making extensive advertising ads.

Financing Management Plan(Vela, 2019)

Don't lose sight of cash. Keep money handy and pay very carefully. Identify drugs that add waste on employers' formularies, measure savings from removing waste.

Reducing the use of high-cost, low-value drugs.

Negotiate with pharmaceutical manufacturers for price discounts.

Giving preference to some drugs over others on formularies based on rebate revenue rather than their value and final cost to the patient.

Reducing the number of workers and reducing wages.

Searching for financing at reasonable prices and flexible payment terms to meet project specifications and budget constraints .(Vela, 2019)

\section{Development plan.(pdsmarketing, 2015)}

\section{Expansion.}

Horizontal expansion that can happen after two years, where we can rent the upper floor with 10,000 pounds for sucking, transporting medicines and the store on the upper floor, with the expansion of the consulting space in the basement and the cosmetic display area and adding a special part for the sale of medical devices such as pressure and sugar devices.

\section{Extension}

After five years have passed since the project began and the profits were collected, we can start thinking about opening another pharmacy branch on Al-Gomhoria Street, 100 meters away, where the rent starts at 12,000 pounds per month. 


\section{Self financed or loan}

The pharmacy, which was established on July 23 Street, was funded by a loan with capital 800000LE.

\section{Upgrading machines}

Each pharmacy is trying to do the same things: fill prescriptions efficiently, provide high-quality patient care, and maintain a sustainable business model in which employees have good job satisfaction and customers are happy.

The Smart flow Pharmacy Workflow System creates a dynamic, as opposed to static, work flow within the pharmacy.

Keys to this system are the establishment of an organized, efficient space and team members who have the appropriate skill set for their position. To have optimal work flow, it is important to have the right setup.Part and parcel of this setup is having the right staff with the good skill sets. Pharmacy team is the key to this "UpSolutions" strategy. We should Train them to build relationships with customers and make relevant product suggestions based off the drugs they are prescribed.This can also work for any product we sell in our store.(pdsmarketing, 2015)

\section{Updating methods}

In today's competitive environment, running an efficient independent pharmacy means lower costs, higher margins and less stress for all parties involved.

Creating efficiency in our pharmacy is a combination of concentrated effort and strategic planning.Team training, inventory management and operations planning all represent key opportunities for improved efficiency.

Analyzing where your pharmacy ranks against industry benchmarks is one of the first steps you should take in exploring areas of opportunity for added productivity in your pharmacy.(pdsmarketing, 2015)

\section{Conclusion}

From the current research it is concuded the following Pharmacists are the link between doctors and patients who give medical instructions to the patient to increase the desired value of the drug and decrease the side effects of it To open new pharmacy you should have advantages and more services over your surrounded compititors. 
Study SWOT analysis for pharmacy is very important to supply unique pharmacological services.It is mandattory to plan for the Budgeting of The Project to include losses and maximise profits.

Estimatation of political study, legal study, environmental study and social study are essential stablishment of new pharmacy.

Catastrophe plan is procedures have been established to respond to any external emergency and the expected risks Such as a severe change in weather conditions such as rain, and also was developed for the fire plan, earthquakes, surface collapse, and pathogenic , microorganisms (Covid19).It is essential to establish the capital and the expanses of the pharmacy.Methods to cover the negative cash flow balance:( Recognizing obligation by putting supplies and other normal operating expenses on a credit card to take advantage of additional payment cycle time and rebates or rewards

From previous positive months of cash flow as maintaining positive cash flow is important to maintain success for long period of time.positive cash flow is a suitable indication of present financial situation.

Short term loans help us to avoid accumulating debt.

Negotiation to postpone obligations and negotiate payment terms as setting invoice payment terms with customers so they know when to pay us and agreeing to our vendors payment terms so we know when to pay them and so adjusting these types of payment terms to improve cash flow for customer payment terms, decrease the number of days customers have to pay us. ) Feasibility of the project this project consists in setting up a pharmacy where all the products for personal care and medicines are sold along with the services provided by pharmacies such as public health checks

The pharmacy also provides a wide variety of treatments and medications as well as over-the-counter medications.

Risk management plan for natural disaster (Earthquakes and surface collapse - Panademic / infectious / communicable diseases ( COVID-19, avian flu, H1N1, etc)) \&man-made disaster (fires ,terrorist attack and work place violence and rumors and malevolence from competitors )

\section{$\underline{\text { Recommendations }}$}

Based on the conclusion of this research and after studying, the following are recommended by this research group:

Pharmacists are the link between doctors and patients who give medical instructions to the patient to increase the desired value of the drug and decrease the side effects of it.

Establish risk management plan for each pharmacy. Having a productive staff means lower refill time and faster order fulfillment. Calculate 
fainnantial issues for pharmacy well before starting. Patient safety and pharmacy safety are considered in policies of successful pharmacies. The occupational health and safety team are involved in designing work place and process to increase in job safety and satisfaction of patients.Managers plan to overcome negative cash flow and to increase pharmacy income. Study SWOT analysis is important for each new medical place before opening. Taking advantage of an automated dispensing system has the potential to improve pharmacy efficiency.Improve work by decresing time consumed in managing through cost control and reduction. Buyers training to control updating minimum and maximum levels to avoid stock delays.

\section{$\underline{\text { References }}$}

Chapter, P. C. (2008). 27: State Board of Pharmacy, § 27.16 (b)(1)(i), Construction and equipment requirements. The Pennsylvania Code Web site.

El-tiqnea. (2020). Feasibility study of a pharmacy project start your project. Retrieved 31 August 2020, from https://tiqnea.com/en/service/feasibility-study-of-a-pharmacyproject/?fbclid=IwAR1AFhTrE5OnAANgvEedOweCUUY4gsJY16_nM W3hHAeSAp1juwyRp1w8oQM

Lauren Vela, Reducing Wasteful Spending in Employers' Pharmacy Benefit Plans (Commonwealth Fund, Aug. 2019).

MCF ENVIRONMENTAL SERVICES. How Pharmacies Should Dispose of Expired Medicine or Drugs || MCF Environmental Services. MCF Environmental Services. Retrieved 31 August 2020, from https://mcfenvironmental.com/how-pharmacies-should-dispose-ofexpired-medicine-or-drugs/.

MPCA. (2020). Disposing of needles and syringes. Minnesota Pollution Control Agency. Retrieved 31 August 2020, from

https://www.pca.state.mn.us/living-green/disposing-needles-and-syringes.

MURPHY, C., 2020. Understanding The Cash Flow

Statement.[online]Investopedia. Available at:

$<$ https://www.investopedia.com/investing/what-is-a-cash-flowstatement/> [Accessed 13 August 2020].

Pdsmarketing. (2015). Read These 4 Tips for Improving Efficiency in Your Pharmacy. Pharmacy Development Services. Retrieved 31 August 
2020, from https://www.pharmacyowners.com/4-tips-for-improvingefficiency-in-your-pharmacy.

Rao, O., Gupta, S., \& Kumar, S. (2018). Strategy Framework for Risk Management of Man-Made Disasters. Retrieved 31 August 2020.

Sinha H. K. (2014). Role of pharmacists in retailing of drugs. Journal of advanced pharmaceutical technology \& research, 5(3), 107.

Shewan, D. (2020). How to Do a SWOT Analysis for Your Small Business (with Examples). Wordstream.com. Retrieved 31 August 2020, from https://www.wordstream.com/blog/ws/2017/12/20/swot-analysis.

Webb, R. (2019). Fire Risk Management for Organizations.

Clearrisk.com. Retrieved 31 August 2020, from

https://www.clearrisk.com/risk-management-blog/4-vial-fire-preventionstrategies-for-corporations. 
